\title{
A Critical Evaluation of Precision Dairy Farming Technologies and Barriers to its Adoption
}

\author{
Naji Awad Ahmed Salem ${ }^{*}$, M. I. Alshelmani ${ }^{1}$ and Almokhtar M. Aljadi ${ }^{2}$ \\ ${ }^{1}$ Department of Animal Production, Faculty of Agriculture, University of Banghzi, \\ Benghazi, Libya \\ ${ }^{2}$ Department of Animal Production, Agriculture college, Sebha University, Sebha \\ *Corresponding author
}

\begin{abstract}
A B S T R A C T
Keywords

Zoonotic

transmission of

diseases, Dairy

farming

technologies

Article Info

Accepted:

05 February 2020

Available Online:

10 March 2020

The management of dairy farming has been historically based on experience and the skills the farm operator has in planning and decisions made. In cases where the farm has large herds, a farming system must be in place, thereby bring an evolution in dairy management, which is datadriven. Precision technologies can bring about increased efficiency and decision making in dairy management. Total farmers that have already adopted the technology is still relatively low, although data shows a growth in the adoption rate. This research seeks to critically evaluate the precision dairy farming technologies in place and the barriers that have caused low adoption of the technology.

\section{Introduction}

Precision dairy farming is described as the process through which technologies are used for measuring the indicators of a particular animal which include the behavioural, production and psychological signs. The aim of measuring the signs is to help in advancement of the Strategies used by the management and improvement of the overall animal performance. The profit margins for the agricultural commodities continue to

reduce over the years due to less governmental regulation of the commodity prices and also the dairy farming operation. A small efficiency in production may cause a landmark impact on the profit. Therefore, the growth in competition has caused an overemphasis on efficiency, thereby causing a more emphasis on both financial and business management. A change or shift in a dairy manager's decision making is seen whereby more emphasis is being put on the protection of the consumers, foods that are pathogenfree, medical treatments reduction (Bewley,
\end{abstract}


2010), improved animal care and zoonotic transmission of diseases. The shift in the emphasis clearly shows the continued change in the management of daily operations. The many modifications being experienced is because of the tremendous technological advancements in all the areas of dairy farming like nutrition, disease control, genetics, and dairy management.

Precision farming is termed as the process of using information technologies in assessing the fine-scale animal and the variations in the physical resources whose main aim is to improve the strategies of management that are useful in the boost of the economic, environmental and social production the individual farm (Eastwood et al., 2004). Precision farming is termed as the trend whereby the focus is given to particular dairy animal by using information technology (Schulze et al., 2007). Precision dairy farming has helped to address the development of animals, the product system, and behaviours of the animal, endemic diseases and the physical setting of the buildings of dairy animals (Wathes et al., 2008). Technologies typically applied in precision dairy farming leads to the decrease of the skilled labour during the handling of animals, thereby making it possible for accomplishing more work using much fewer labourers. Application of technologies in precision farming in the dairy animal's observation is of great use as far as the technologies in use can monitor parameters, is reliable in observation of animal behaviours and can do an accurate description of behaviours by use of secure algorithms (Berckmans, 2006). Therefore, the effectiveness of work-routine is improved if the technology in place is much more reliable than the replaced skilled labour.

The leading technologies in precision include (Endres, 2019):
Wearable sensors for the leg, neck or the ear. Boluses for the Rumen.

Subcutaneous implants.

Online or inline sensors for the milk.

Analysis of videos and face recognition.

Automated feeding and milking systems.

\section{The benefits of precision dairy farming}

According to research by (Bewley, 2010), the following are examples of the potential benefits of precision farming:

An improved level of efficiency.

A decrease in the operating costs of the farm.

An increase in the quality of the products produced.

Decrease in the adverse impacts of the environment.

Improved overall health and the well-being of animals.

Precision technologies are presumed to have a major effect in some areas, which include reproduction, quality control and health. An increase in the size of the dairy operations in any farm makes technology be the best option due to reduced reliance on skilled labour and its ability to use economies of scale technology. Technologies in precision farming enable the farmers to make proper decisions which directly results in improved productivity and profitability of the farm. By use of real-time data, monitoring can be achieved through the creation of reports identifying the deviations (Bewley, 2010). Information from the technologies in precision farming is critical as far as there are effective utilisation and interpretation during the making of the farm decisions. The farm management should make use of computerised information systems to help in the understanding of the enormous figures from the farming technologies. Consequently, the information in place is incorporated into a system that supports decision making to assist 
in making decisions that need many data sources compiled.

Initially, farmers made use of experience and judging to help in the identification of outlying animals. The historical method of judging and expertise cannot be entirely eliminated by the technologies and forms invaluable skills in dairy products, but it has many drawbacks due to cow's condition perception of the human being. By the time the human being can clearly identify the stresses and illnesses in an animal, the condition may be more advanced for any intervention. The observable illness/stress signs are typically followed by physiological processes that cannot be seen by a human eye like the change in heart rate and changes in temperature. There are technologies in place that are used in monitoring the physiological processes of dairy animals that are necessary to supplement the observable signs of the farmer (Whitford and Klimley, 2019).

\section{Technologies in precision dairy farming}

\section{Robotic milking}

Robotic/automatic milking machines have gained popularity globally. The milking systems frequently conduct milking automatically without any human intervention (Butler, Hollaway and Bear, 2012). Animals in dairy farming are the ones that choose when to be milked, and they enter the robot and get milked at any time of the day. Therefore, milking system in robotic is understood to increase the farms level of production and is also beneficial for the health and welfare of the animals. According to a research, in the UK there were about 50 robotic milking machines in use in 2003, in 2008 the study also established that the figure for the robotic devices increased to 350 (Gibson, 2011). Robotic milking is believed to have many advantages to farmworkers which include: increased welfare of the animals, increased productivity of the animals and the reduction of labour costs. European Union has funded many pieces of research on the effects posed by robotic milking on the health and the well-fare of animals in dairy farming and also dairy animal productivity. Some governments and NGOs have raised concerns that welfare can compromise technology in some circumstances. The NGOs recommend that husbandry practices require to be incorporated so that the welfare standards are maintained.

\section{Automatic calf Feeders system}

Automated calves feeding systems that are controlled by a computer have a sharp increase in the demand hence saving on labour. The automatic calf feeding system is made up of a stand-alone unit that has the capability for water heating and dispensing powdered milk quantity that has already been set and mixes the powder. The mixture is then transferred to a cylinder from where the calf is fed via a teat (Fujiwara et al., 2014 and Soberon et al., 2012). The feeding system of a calf has the ability to feed groups of calves where the first seven days, the calf is supplied using the bottle to enable it to familiarise with the feeding system. Using automatic feeding system, optimum development and growth of the calves is guaranteed.

The system ensures that the calves can enjoy a natural feeding rhythm by drinking milk whenever they feel like in a controlled way at the same time reducing the total employees. Whenever the calf enters a feeding station, the tag placed at calf's ear is scanned by a receiver antenna placed on the station and a recipe is prepared to depend on the calf's age. When a calf is allowed to feed, the system makes the powdered milk as per the specified formula. The main benefits of automatic feeding include (Ionescu, 2016): 
Increased rate of growth for the calves.

It ensures that the rumen develops well.

Helps in ensuring individual calf management.

Helps ensuring that proper milk temperature for calves is maintained.

Ensures a flexible feeding schedule.

Low maintenances are thereby reducing the operating costs.

\section{Cow behaviour sensors}

To understand animal's nutrition, health, well-being and production, animal behaviours must be monitored. Animals' monitoring is increasingly becoming an essential practice (Mattachini et al., 2016).

Some daily patterns of eating and rumination are believed to be related closely to the health and animals' productivity.

Traditionally, the feeding behaviour used to be determined using methods such as direct observation and recording of a time-lapse video (Overton et al., 2002). The traditional methods used to consume a lot of time and are also labour intensive, thereby limiting their application over long periods and where there are many animals. Currently, new methods are developed to help in the assessment of behavioural activities using automatic recording techniques.

The automated techniques are used for measuring the animal feeding behaviours and feed intake. The method ensures that feeding behaviours are accurately quantified. The system also makes it efficient in the control and assessment of dairy farms.

\section{Barriers to the adoption of precision dairy farming}

Livestock production control and monitoring are underdeveloped as compared to other industries globally despite research demonstrating increased productivity. In dairy production, the indicators that require to be monitored are biological and vary and sometimes very unpredictable. Therefore, a sound system must be capable of continuous surveillance and have the capabilities of quantifying the behaviours automatically. In making technological decisions, the conduct of the technology and economic benefits plays a significant role. Adoption of technology has been seen where the level of profitability is high, high yield, and there is cost are reduction (Russell and Bewley, 2013). Also, technologies are adopted where there is low availability of labour or the labour available is expensive (Steeneveld et al., 2012).

Dairy producers are required to select a technology that matches their production needs. Therefore, many choices exist on the dairy technologies that can be applied by the producers. Difficulties exist in making a choice for the technology to make use of since many farmers are not aware of the techniques available (Russel and Bewley, 2013). The available technologies have capabilities of monitoring animal activity, temperature, rumination, resting time and all the animals' well-being (DeVries, 2018). Despite the existence of many technologies, their adoption has remained relatively low. The perceptions of the farmers need to be improved for increased adoption of precision dairy farming technologies. The current trends under precision farming, the dairy farmers are the users of the technologies, but they excluded during technology development. Considering farmer's exclusion, the result is the growth of several technologies that are not addressing the needs of the farmers leading to low adoption rate. For example, in United States, total dairy farms have continued to decrease, but the existing farms continue to increase in size and 
small firms exit dairy farming (Hadley et al., 2002).

Some of the well-known precision dairy farming technologies include the automatic milking machine that was implemented first in the Netherlands (Bijl, Kooistra\&Hogeveen, 2007). The reason behind the differences in the adoption rate of the technologies is primarily caused by average employee wages. For example, in United States of America, the average employee wage is estimated to be $\$ 17.58$ (MacDonald, 2007) while the average employee wages in the Netherlands where there is a high rate of precision dairy farming adoption is estimated to be $\$ 24.13$ (Huijps et al., 2008). The data above clearly shows that due to labour in the USA being less expensive, farmers in dairy farming have a low incorporate rate of precision dairy farming technologies.

In conclusion, precision dairy farming technologies are still in the early stage, although there are new technologies introduced in the market annually. There are several technologies under precision dairy farming like the sensors, automatic feeding systems and robotic milking systems. Precision dairy farming has many benefits to the farmers in that it helps to increase efficiency, reduction of costs, improving the product quality and improvement of animals' well-being. Technologies under precision dairy farming are believed to have significant effects in areas such as reproduction, quality control and health. There still exist many barriers towards the adoption of precision dairy farming that must be addressed for the full approval of the technologies. One of the main obstacles is cheap labour resulting in farmers preferring to use labour in place of technology adoption.

Therefore, before the farmer decides to finance new technology, the farmer should ensure that an analysis is conducted to assess if it addresses the needs of the farm.

\section{References}

Automatic on-line monitoring of animals by precision livestock farming,". Livestock production and society, pp. 287-287, 2006.

Bijl, R., S. Kooistra, and H. Hogeveen, "The Profitability of Automatic Milking on Dutch Dairy Farms," Journal of Dairy Science, vol. 90, no. 1, pp. 239-248, 2007.

Devries, T. "507 Challenges and opportunities in precision health monitoring of dairy cattle.," Journal of Animal Science, vol. 96, no. suppl_3, pp. 502-502, 2018.

Fujiwara, M., J. Rushen, and A. M. D. Passillé, "Dairy calves' adaptation to group housing with automated feeders," Applied Animal Behaviour Science, vol. 158, pp. 1-7, 2014.

Hadley, G., S. Harsh, and C. Wolf, "Managerial and Financial Implications of Major Dairy Farm Expansions in Michigan and Wisconsin," Journal of Dairy Science, vol. 85, no. 8, pp. 20532064, 2002.

Ionescu, V., "Fetal ECG Extraction from Multichannel Abdominal ECG Recordings for Health Monitoring During Labor," Procedia Technology, vol. 22, pp. 682-689, 2016.

Mattachini, G., E. Riva, F. Perazzolo, E. Naldi, and G. Provolo, "Monitoring feeding behaviour of dairy cows using accelerometers," Journal of Agricultural Engineering, vol. 47, no. 1, p. 54, Aug. 2016.

Overton, M., W. Sischo, G. Temple, and D. Moore, "Using Time-Lapse Video Photography to Assess Dairy Cattle Lying Behavior in a Free-Stall Barn," Journal of Dairy Science, vol. 85, no. 9, pp. 2407-2413, 2002. 
Precision Dairy Farming-taking the microscope to dairy farm management.," 2004.

The impact of technological change in dairy farming: robotic milking systems and the changing role of the stockperson,". Royal Agricultural Society of England, p. 173, 2012.

The first North American Conference on Precision Dairy Management," in the first North American Conference on Precision Dairy Management, 2010.

Russell, R. and J. Bewley, "Characterization of Kentucky dairy producer decisionmaking behavior," Journal of Dairy Science, vol. 96, no. 7, pp. 4751-4758, 2013.

Schulze, C., J. Spilke, and W. Lehner, "Data modeling for Precision Dairy Farming within the competitive field of operational and analytical tasks," Computers and Electronics in Agriculture, vol. 59, no. 1-2, pp. 39-55, 2007.

Soberon, F., E. Raffrenato, R. Everett, and M. V. Amburgh, "Preweaning milk replacer intake and effects on long-term productivity of dairy calves," Journal of Dairy Science, vol. 95, no. 2, pp. 783
793, 2012.

Steeneveld, W., L. Tauer, H. Hogeveen, and A. O. Lansink, "Comparing technical efficiency of farms with an automatic milking system and a conventional milking system," Journal of Dairy Science, vol. 95, no. 12, pp. 7391-7398, 2012.

"The future of precision dairy farming," $U M N$ Extension, 2019. [Online]. Available: https://extension.umn.edu/dairynews/future-precision-dairy-farming. [Accessed: 10-Feb-2020].

Wathes, C., H. Kristensen, J.-M.Aerts, and D. Berckmans, "Is precision livestock farming an engineers daydream or nightmare, an animals friend or foe, and a farmers panacea or pitfall?," Computers and Electronics in Agriculture, vol. 64, no. 1, pp. 2-10, 2008.

Whitford, M. and A. P. Klimley, "An overview of behavioral, physiological, and environmental sensors used in animal biotelemetry and biologging studies," Animal Biotelemetry, vol. 7, no. $1,2019$.

\section{How to cite this article:}

Naji Awad Ahmed Salem, M. I. Alshelmani and Almokhtar M. Aljadi. 2020. A Critical Evaluation of Precision Dairy Farming Technologies and Barriers to its Adoption. Int.J.Curr.Microbiol.App.Sci. 9(03): 313-318. doi: https://doi.org/10.20546/ijcmas.2020.903.037 